\title{
Prothrombin Measurement
}

National Cancer Institute

\section{Source}

National Cancer Institute. Prothrombin Measurement. NCI Thesaurus. Code C96626.

The determination of the amount of prothrombin present in a sample. 